Development of Transparent Ceramic Ce-Doped Gadolinium Garnet Gamma Spectrometers

N. J. Cherepy, Z. M. Seeley, S. A. Payne, P. R. Beck, O. B. Drury, S. P. O'Neal, K. Morales Figueroa, S. Hunter, L. Ahle, P. A. Thelin, T. Stefanik, J. Kindem

November 16, 2012

IEEE Nuclear Science Symposium

Anaheim, CA, United States October 28, 2012 through November 2, 2012 
This document was prepared as an account of work sponsored by an agency of the United States government. Neither the United States government nor Lawrence Livermore National Security, LLC, nor any of their employees makes any warranty, expressed or implied, or assumes any legal liability or responsibility for the accuracy, completeness, or usefulness of any information, apparatus, product, or process disclosed, or represents that its use would not infringe privately owned rights. Reference herein to any specific commercial product, process, or service by trade name, trademark, manufacturer, or otherwise does not necessarily constitute or imply its endorsement, recommendation, or favoring by the United States government or Lawrence Livermore National Security, LLC. The views and opinions of authors expressed herein do not necessarily state or reflect those of the United States government or Lawrence Livermore National Security, LLC, and shall not be used for advertising or product endorsement purposes. 


\title{
Development of Transparent Ceramic Ce-Doped Gadolinium Garnet Gamma Spectrometers
}

\author{
N.J. Cherepy, Member, IEEE, Z.M. Seeley, S.A. Payne, Member, IEEE, P.R. Beck, O.B. Drury, S.P. O’Neal, \\ K. Morales Figueroa, S. Hunter, L. Ahle, P.A. Thelin, T. Stefanik, J. Kindem, Member, IEEE,
}

\begin{abstract}
Transparent polycrystalline ceramic scintillators based on the garnet structure and incorporating gadolinium for high stopping power are being developed for use in gamma spectrometers. Optimization of energy resolution for gamma spectroscopy involves refining the material composition for high stopping and high light yield, developing ceramics fabrication methodology for material homogeneity, as well as selecting the size and geometry of the scintillator to match the photodetector characteristics and readout electronics. We have demonstrated energy resolution of $4 \%$ at $662 \mathrm{keV}$ for $0.05 \mathrm{~cm}^{3}$ GYGAG(Ce) ceramics with photodiode readout, and $4.9 \%$ resolution at 662 $\mathrm{keV}$ for $18 \mathrm{~cm}^{3}$ GYGAG(Ce) ceramics and PMT readout. Comparative gamma spectra acquired with GYGAG(Ce) and $\mathrm{NaI}(\mathrm{Tl})$ depict the higher resolution of GYGAG(Ce) for radioisotope identification applications. Light yield nonproportionality of garnets fabricated following different methods reveal that the fundamental shapes of the light yield dependence on energy are not intrinsic to the crystal structure, but may instead depend on trap state distributions. With exposure to 9 $\mathrm{MeV}$ Brehmsstrahlung radiation, we also find that GYGAG(Ce) ceramics exhibit excellent radiation hardness.
\end{abstract}

Index Terms — Gamma-ray spectroscopy, Garnets, Scintillators

\section{INTRODUCTION}

Advantages of the new Gd-based transparent ceramic garnet scintillators include: (1) high fast light yield of $>40,000$ $\mathrm{Ph} / \mathrm{MeV}$ and principal decay of $\sim 100 \mathrm{~ns}$, (2) photopeak efficiency superior to $\mathrm{NaI}(\mathrm{Tl})$ and $\mathrm{LaBr}_{3}(\mathrm{Ce})$, (3) excellent light yield proportionality, (4) ease of uniform fabrication via ceramics processing, and (5) no intrinsic radioactivity. In our earlier reports [1-3], we measured energy resolution of $4.5 \%$ at $662 \mathrm{keV}$ with PMT readout and $4.2 \%$ with Silicon photodiode readout, utilizing small $\left(0.05-2 \mathrm{~cm}^{3}\right)$ GYGAG(Ce) ceramics.

Identification of the ideal garnet host for Ce-activation providing the highest light yield and bluest emission for PMT readout requires analysis of the conduction and valence band positions, as well as the positioning of the Ce transition within the band gap [4]. When compared to e.g. YAG or LuAG, the Gd-based garnets incorporating Ga provide favorable crystal

Manuscript received November 15, 2012. This work has been supported by the US Department of Homeland Security, Domestic Nuclear Detection Office, under competitively awarded IAA HSHQDC09-x-00208 / P00002. This support does not constitute an express or implied endorsement on the part of the Government. This work was performed under the auspices of the U.S. DOE by Lawrence Livermore National Laboratory under Contract DE-AC52-07NA27344.

N.J. Cherepy, Z.M. Seeley, S.A. Payne, P.R. Beck, O.B. Drury, S.P. O'Neal, K. Morales Figueroa, S. Hunter, L. Ahle and P.A. Thelin are with Lawrence Livermore National Laboratory, Livermore, CA 94550 (phone: +1-925-424-3492; e-mail: cherepy1@1lnl.gov).

T. Stefanik is with Nanocerox, Inc.

J. Kindem is with Digirad, Inc. field for $\mathrm{Ce}^{3+}$ emission at relatively short wavelength, as well as the ability for excitation to migrate on $\mathrm{Gd}^{3+}$ as a stoichiometric sensitizer for $\mathrm{Ce}^{3+}$. Both $\mathrm{Gd}$ and $\mathrm{Tb}$ offer comparable stopping to $\mathrm{Lu}$, without radioactivity. However, Tb-based garnets exhibit slower decay times than Gd-garnets making them less desirable for gamma spectroscopy [5].

Transparent ceramics fabrication allows production of monolithic, fully-dense optics without macroscopic Ce-doping gradients. Ce-doping gradients are well-known in single crystal garnets, due to the poor match in ionic radius between $\mathrm{Ce}^{3+}(103 \mathrm{pm})$ and that of the substitutional sites of e.g. $\mathrm{Gd}^{3+}$ $(94 \mathrm{pm})$ and $\mathrm{Y}^{3+}(88 \mathrm{pm})$, leading to a segregation coefficient of Ce in GGAG of 0.36 and in YAG of 0.082 [6, 7]. Although high light yields and good energy resolution in small single crystal samples have been obtained for Ce-doped Gd-garnets recently, large size crystals exhibit significant Ce gradients, resulting in light yield non-uniformity and impacting the performance for gamma spectroscopy [8].

Even scintillators without doping gradients or material nonuniformity can suffer degradation in performance in large sizes due to optical light trapping, when activators with small Stokes' shifts are employed. This is well-documented for the single crystal scintillator, $\mathrm{SrI}_{2}(\mathrm{Eu})$ [9-11]. In contrast to $\mathrm{SrI}_{2}(\mathrm{Eu})$, self-absorption by Ce in $\mathrm{GYGAG}(\mathrm{Ce})$ results in redshifting of the emission that diminishes the quantum efficiency of conversion with PMT readout, due to the loss in bialkali photocathode sensitivity at longer wavelengths. We have therefore tried to identify the minimum Ce-doping concentration that still provides high light yield in GYGAG.

We have fabricated GYGAG(Ce) in large sizes of $>35 \mathrm{~cm}^{3}$ $\left(2 \mathrm{in}^{3}\right)$. The garnet ceramics exhibit excellent mechanical toughness and are easily cut into small cuboids for integration with silicon photodiodes. Gamma spectroscopy with large size GYGAG(Ce) using PMT readout and small size GYGAG(Ce)
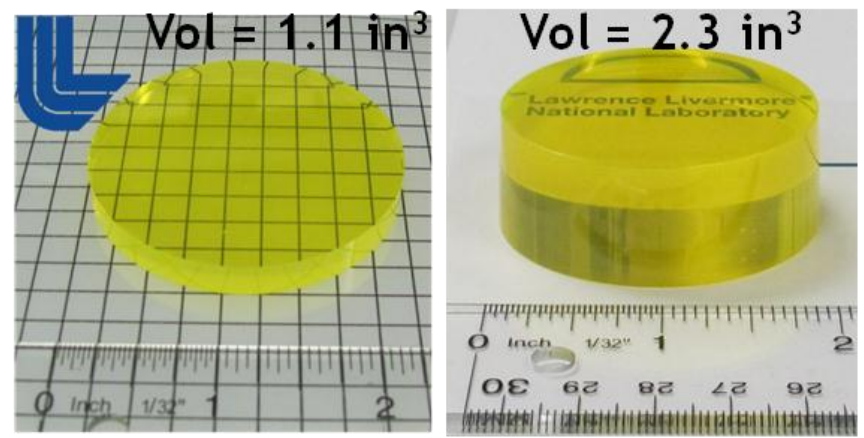

Fig. 1. Photos of the GYGAG(Ce) ceramics studied in this paper (left) 18 $\mathrm{cm}^{3}$ (2.2" diameter x 0.3 " thick) and (right) $38 \mathrm{~cm}^{3}$ (2" diameter x 0.73 " thick). 
with photodiode readout indicate both approaches can provide high resolution gamma spectroscopy. Initial results comparing small ceramic and single crystal $\operatorname{GGAG}(\mathrm{Ce})$ scintillation performance are also presented here.

The Scintillator Light Yield Non-proportionality Characterization Instrument (SLYNCI) [12-14] provides valuable feedback to compare various garnet structures and identify the best ceramics processing methods. We have studied a range of garnets formed by different methods to determine their impact on light yield proportionality.

\section{METHODS}

\section{A. Transparent Ceramics Fabrication}

GYGAG(Ce), $\operatorname{Gd}_{1.5} \mathrm{Y}_{1.5} \mathrm{Ga}_{2.2} \mathrm{Al}_{2.8} \mathrm{O}_{12}(\mathrm{Ce})$, and $\mathrm{GGAG}(\mathrm{Ce})$, $\mathrm{Gd}_{3} \mathrm{Ga}_{2.2} \mathrm{Al}_{2.8} \mathrm{O}_{12}(\mathrm{Ce})$, nanoparticles were synthesized via the flame spray pyrolysis (FSP) method by Nanocerox. Nanoparticles were suspended with organic binders in an aqueous solution, gel cast in a mold, and organics were removed by a heat treatment at $1050^{\circ} \mathrm{C}$ in air. Green bodies thus prepared were sintered under a vacuum of $<2 \times 10^{-6}$ Torr at $1600^{\circ} \mathrm{C}$ for $2 \mathrm{~h}$ in a tungsten element vacuum furnace, reaching closed porosity and densities of approximately $97 \%$. The sintered samples were then hot isostatically pressed under $200 \mathrm{MPa}$ of inert argon gas pressure at $1650^{\circ} \mathrm{C}$ for $4 \mathrm{~h}$ in a tungsten element HIP. Further details are available in [15].

\section{B. Scintillator Absorption and Radioluminescence Spectra}

Optical absorption spectra were obtained with a Thermo Evolution $220 \mathrm{UV}$-visible spectrometer. Radioluminescence spectra were acquired using a ${ }^{90} \mathrm{Sr} /{ }^{90} \mathrm{Y}$ source $(\sim 1 \mathrm{MeV}$ average beta energy), and spectra were collected with a Princeton Instruments/Acton Spec 10 spectrograph coupled to a thermoelectrically cooled CCD camera.

\section{Scintillation Characterization with PMT Readout}

We measured pulse height spectra with ${ }^{137} \mathrm{Cs}$ and ${ }^{60} \mathrm{Co}$ sources with various scintillators. Hamamatsu R6231-100 and 6232-100 photomultiplier tubes, employed for all PMT measurements, were connected to an Ortec 113 preamplifier. The signals were shaped with a Tennelec TC 244 spectroscopy amplifier (shaping time typically $4 \mu$ s for Ce-doped garnets) and then recorded with an Amptek MCA8000-A multichannel analyzer. Effective light yields were determined by reference to a standard $\mathrm{YAG}(\mathrm{Ce})$ ceramic from Baikowski, and energy resolution was obtained by the use of Gaussian peak fitting in Igor Pro. A Bridgeport Instruments eMorpho was used to record scintillation pulse traces, and those pulses which constituted a full-energy deposition were selected, and the scintillation decay obtained by averaging 10 traces from the selected pulses, and fitting the decay to a double exponential using Igor Pro.

\section{Gamma Spectra with Silicon Photodiode Readout}

Cuboids of GYGAG(Ce) were optically coupled to a silicon photodiode array, as described in [3]. We measured pulse height spectra with a ${ }^{137} \mathrm{Cs}$ source and employed a custom ASIC for signal readout and co-adding of coincident events.

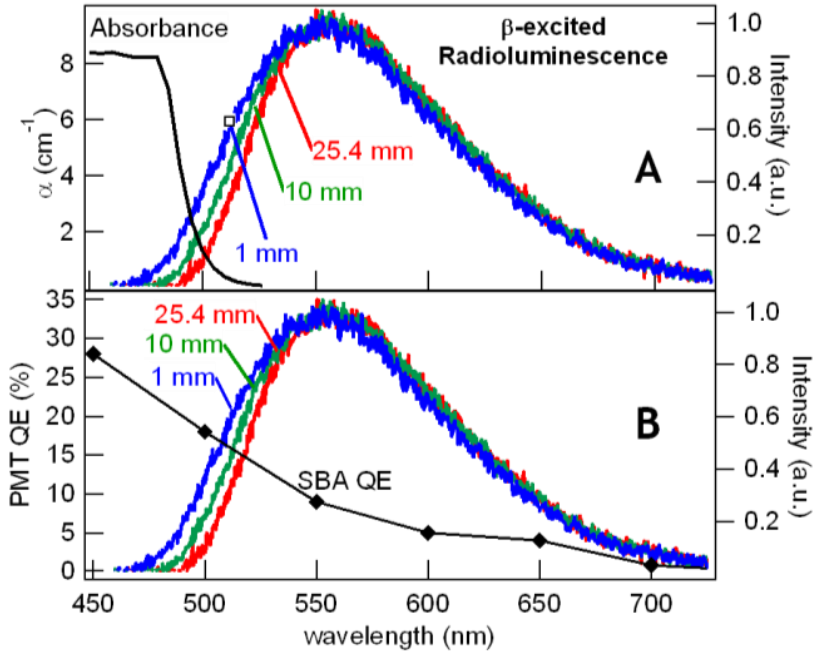

Fig. 2. (A) Absorption spectrum for $\mathrm{GYGAG}(\mathrm{Ce}=0.02)$ and beta-excited radioluminescence spectra acquired with 3 samples, 1, 10 and $25.4 \mathrm{~mm}$ thick. Significant red-shifting is observed as a function of thickness. Absorption cross-section is quantitative. (B) Super-bialkali photocathode responsivity shown in comparison with the same three radioluminscence spectra.

\section{E. Light Yield Non-proportionality Measurements}

The electron non-proportionality was obtained using the Scintillation Light Yield Non-proportionality Characterization Instrument (SLYNCI) using a Compton Coincidence technique as described in [16,17].

\section{F. Radiation Hardness Study}

Scintillator samples were exposed to radiation emitted by a Varian M9 LINAC Brehmsstrahlung source, nominal $9 \mathrm{MeV}$. Samples were placed as close as possible to the source and exposed to a flux of $10 \mathrm{kRad} / \mathrm{min}$ for a total dose of $53 \mathrm{MR}$, as characterized using an ion chamber.

\section{RESULTS AND DISCUSSION}

\section{A. Scintillator Absorption, Radioluminescence and Decay}

The absorption spectrum measured for a $1 \mathrm{~mm}$ thick sample of GYGAG(Ce $=0.02)$ is shown in Figure 2, where it has been converted into the absorption cross section as a function of wavelength (signal saturates below $475 \mathrm{~nm}$ ). The effect of the relatively small Stokes' Shift on the radioluminescence is observable when comparing the spectra obtained with identical samples of GYGAG $(\mathrm{Ce}=0.02)$ of thicknesses $1 \mathrm{~mm}$, $1 \mathrm{~cm}$ and $2.54 \mathrm{~cm}$ Figure 2). Light trapping (self-absorption and subsequent re-emission to longer wavelengths) and ultimately non-uniformity in light collection is the result.

Previous studies have detailed the effect of optical light trapping and methods for mitigation for Eu-doped Strontium Iodide [9-11, 18], however, that scintillator emits in the blue, where PMT quantum efficiency $(\mathrm{QE})$ is high and nearly invariant. In contrast, between 475 and $650 \mathrm{~nm}$, the PMT QE decreases by a factor of about 4 , thus the net result of the light trapping and red-shifting emission as a function of size is decreased effective light yield, as well as position dependent 


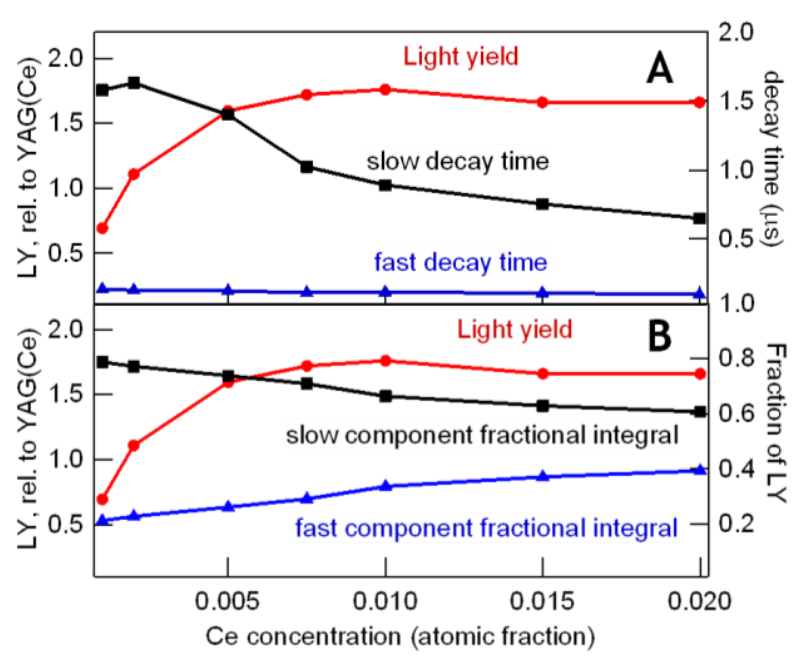

Fig. 3. (A) Seven GYGAG(Ce) samples fabricated with $\mathrm{Ce}=0.001-0.02$ reveal a consistent fast decay time $(\sim 100 \mathrm{~ns})$ and a slow decay that decreases from $1.6 \mu$ s to $0.6 \mu$ s between $\mathrm{Ce}=0.001$ and 0.02 . Light yield ( $8 \mu$ s shaping time) is nearly constant for $\mathrm{Ce}>0.005$. (B) The integrated fractional intensity of the two components indicate that the relative contribution of the fast component increases with Ce concentration.

inhomogeneity in the effective light yield.

In order to mitigate light-trapping and enable higher effective light yields and better light collection homogeneity, we undertook a Ce-doping study to identify the lowest Ce concentration that could provide high light yield with sufficiently fast decay for standard analog shaping amplifiers $(<12 \mu \mathrm{s})$. GYGAG(Ce) exhibits a double exponential decay, as shown in [2]. Figure 3 shows that the light yield reaches its maximum just above $\mathrm{Ce}=0.005$ and does not decrease with concentration, up to $\mathrm{Ce}=0.02$. The fast decay, assigned to the Ce intrinsic lifetime in GYGAG, remains consistent at $\sim 100$ ns, though its relative amplitude increases steadily with concentration. The slow component, assigned to the effect of energy migration via $\mathrm{Gd}^{3+}$ as well as shallow traps becomes faster as the $\mathrm{Ce}$ concentration increases, while its relative
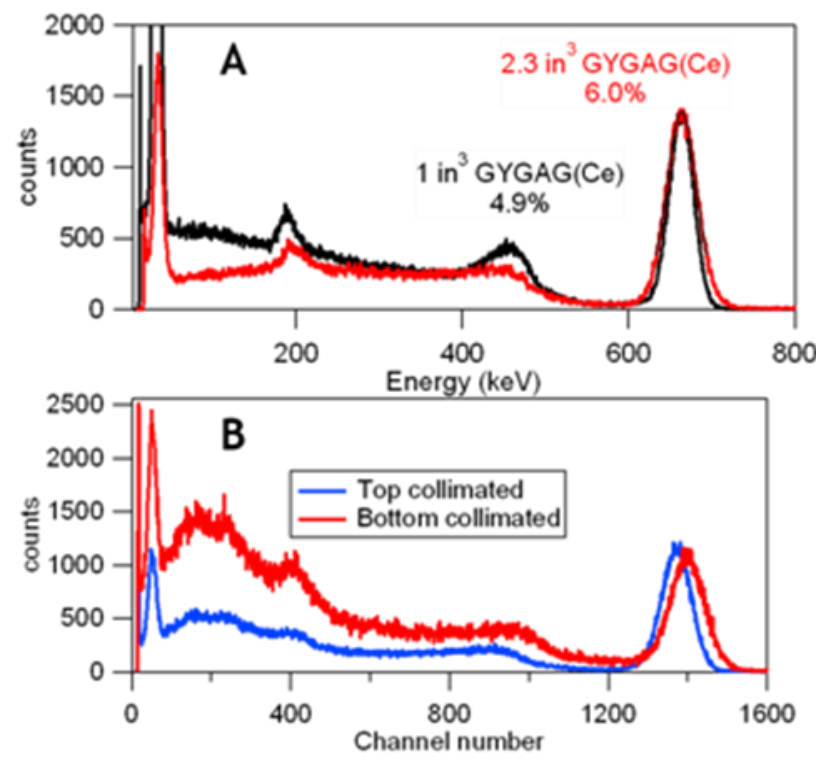

Fig. 4. (A) Pulse height spectra acquired with ${ }^{137} \mathrm{Cs}$ using the $1 \mathrm{in}^{3}$ and 2.3 in 3 GYGAG $(\mathrm{Ce}=0.01)$ ceramics shown in Fig. 1. (B) Pulse height spectra obtained with a collimated ${ }^{137} \mathrm{Cs}$ source exhibits a $4 \%$ change in photopeak centroid, indicating significant light-trapping, leading to degradation of energy resolution.

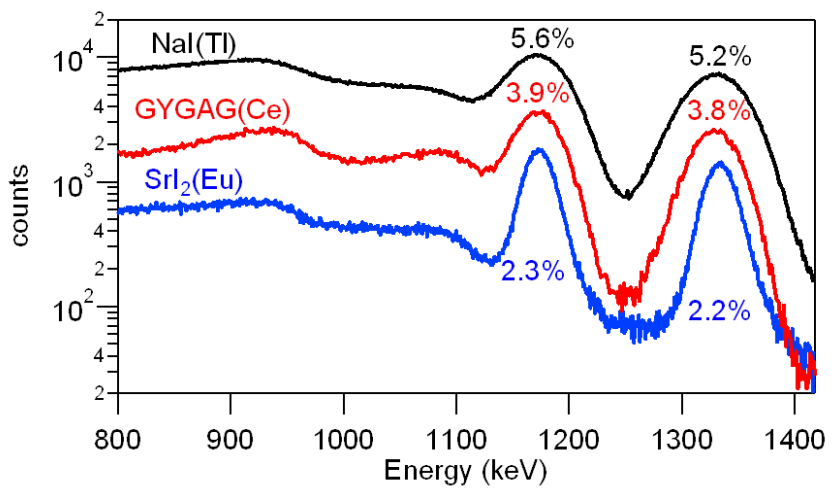

Fig. 5. Gamma spectra of ${ }^{60} \mathrm{Co}$ using 1 in $^{3}$ scintillators of $\mathrm{SrI}_{2}(\mathrm{Eu})$ GYGAG(Ce) and $\mathrm{NaI}(\mathrm{Tl})$.

amplitude decreases.

\section{B. Gamma Spectroscopy}

Scintillator-based gamma ray spectrometers are often used when large volumes for high sensitivity are required for detection of weak sources. We therefore are working to scale up GYGAG $(\mathrm{Ce})$. Figure 4 shows the pulse height spectra with ${ }^{137} \mathrm{Cs}$ acquired with the $1 \mathrm{in}^{3}$ and $2.3 \mathrm{in}^{3}$ scintillators shown in Figure 1. The resolution is found to be degraded from $4.9 \%$ at $662 \mathrm{keV}$ to $6 \%$ in the larger scintillator. It is notable that for the $2.3 \mathrm{in}^{3}$ GYGAG(Ce), instead of the expected Gaussianshaped photopeak at $662 \mathrm{keV}$, an asymmetric tail to high energy is observed. This is due to light trapping, and is further revealed in Figure 4B, which shows that the effective pulse height is decreased by $\sim 4 \%$ for the spectrum acquired at the
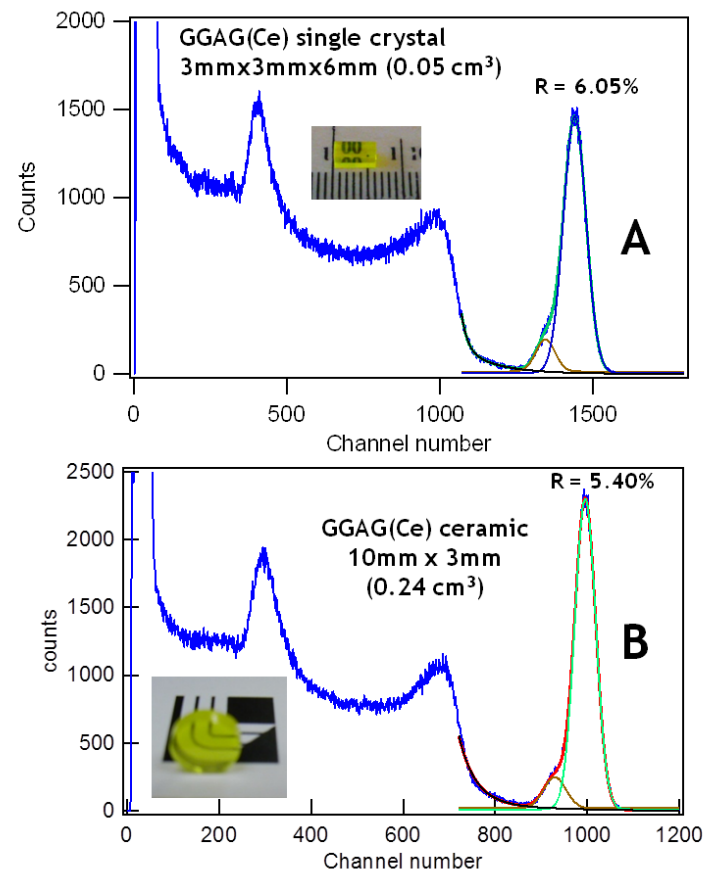

Fig. 6. (A) Pulse height spectrum acquired with ${ }^{137} \mathrm{Cs}$ with a $0.05 \mathrm{~cm}^{3}$ GGAG(Ce) single crystal grown by Furukawa. (B) Pulse height spectrum acquired with ${ }^{137} \mathrm{Cs}$ with a $0.24 \mathrm{~cm}^{3} \mathrm{GGAG}(\mathrm{Ce})$ transparent ceramic fabricated at LLNL. 
top of the sample, compared with when the collimated source irradiates the bottom of the scintillator near the PMT.

Comparative gamma spectroscopy obtained with three $1 \mathrm{in}^{3}$ scintillators using a ${ }^{60} \mathrm{Co}$ source is shown in Figure 5. The energy resolution obtained with $\mathrm{GYGAG}(\mathrm{Ce})$ is considerably better than that of $\mathrm{NaI}(\mathrm{Tl})$, but is surpassed by $\mathrm{SrI}_{2}(\mathrm{Eu})$.

The photofractions (ratio of the photopeak efficiency over the total gamma stopping) of $\mathrm{NaI}(\mathrm{Tl})$ : GYGAG(Ce) : GGAG(Ce) are calculated to be $1: 1.1: 1.4$, therefore GGAG(Ce) will offer higher detection efficiency for a given size. For this reason, we are also studying the fabrication and scintillation properties of $\mathrm{GGAG}(\mathrm{Ce})$. Pulse height spectra acquired with ${ }^{137} \mathrm{Cs}$ for a $\mathrm{GGAG}(\mathrm{Ce})$ single crystal from Furukawa and a GGAG(Ce) ceramic fabricated at LLNL are shown in Figures $6 \mathrm{~A}$ and $6 \mathrm{~B}$, respectively. Comparable energy resolution and light yield to GYGAG(Ce) is obtained.

\section{Gamma Spectra with Silicon Photodiode Readout}

The Digirad gamma camera described in [3], is based on 2.8 x $2.8 \times 6 \mathrm{~mm}$ scintillator cuboids coupled to a photodiode array, normally employing $\mathrm{CsI}(\mathrm{Tl})$. Here, we have studied in more detail the integration of $\mathrm{GYGAG}(\mathrm{Ce})$ as a possible improvement, due to its faster scintillation decay and better energy resolution over $\mathrm{CsI}(\mathrm{Tl})$. To further improve detection efficiency, we have configured the readout electronics with a custom ASIC to obtain the energy histogram comprised of both single events and double events arriving in temporal coincidence (within a 2 microsecond coincidence window). A further advantage of recording coincidence events is the ability to utilize Compton imaging to obtain directional information about the radioactive source.

Detection efficiency increased by $\sim 35 \%$ by including double coincidence events, but energy resolution at $662 \mathrm{keV}$ was degraded from $4.0 \%$ to $4.7 \%$ for GYGAG (see Figure 7). For $\mathrm{CsI}(\mathrm{Tl})$, studied in the same configuration, $5.0 \%$ was obtained for single hits, degrading to $5.6 \%$ for the summed spectrum of single and double hits. Resolution degradation observed in the co-added histogram is thought to be due to the doubling of both the electronic readout noise and the photodetector dark noise for co-added events. Additional

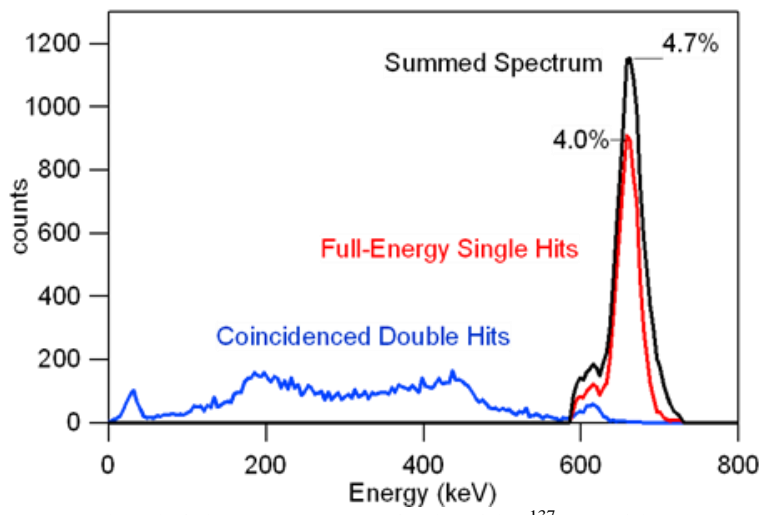

Fig. 7. Pulse height spectra acquired with ${ }^{137} \mathrm{Cs}$ with a $0.05 \mathrm{~cm}^{3}$ GYGAG(Ce) ceramic fabricated at LLNL, using silicon photodiode readout. Energy resolution for photopeak events collected in single GYGAG(Ce) pixels is $4.0 \%$ at $662 \mathrm{keV}$ (red trace), and when double hits arriving in coincidence (blue trace) are co-added, and then combined with the single event spectrum, the black trace is obtained.

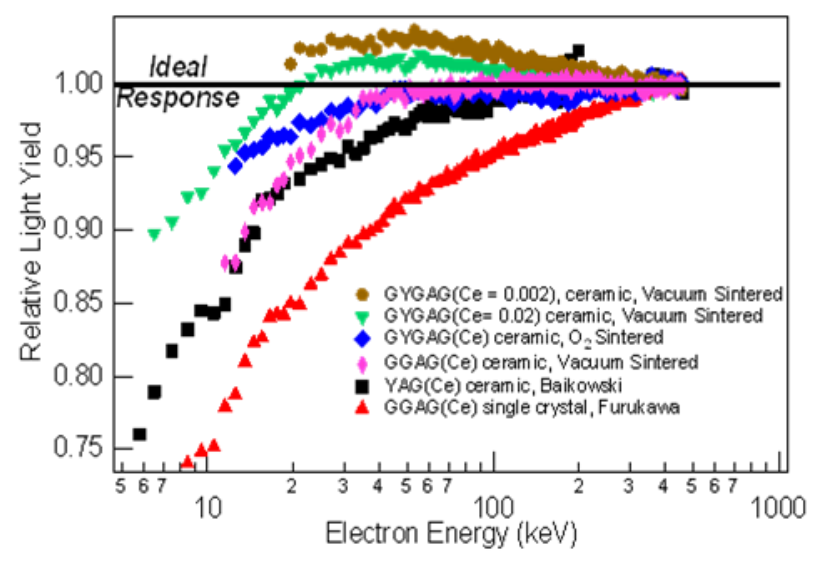

Fig. 8. SLYNCI data for GYGAG(Ce), GGAG(Ce) and YAG(Ce) samples indicate the a strong effect of the fabrication conditions, as well as changes with Ce-doping level. This suggests that the nature and concentration of defects and recombination centers differ markedly between samples.

contributions may arise from imperfect normalization of signals from each pixel and the difficulty of applying an exact correction for energy-dependent light yield nonproportionality.

\section{Scintillation Light Yield Non-proportionality}

It is well-known that the light output of scintillators is not rigorously proportional to the amount of energy deposited in the scintillator [12-14], and that scintillator energy resolution is poorer than that predicted by the photon statistics of the deposited energy. Figure 8 and Table I show the SLYNCI measurements acquired with several Ce-doped garnet transparent ceramics and single crystals.

We find that the methods of fabrication of the garnet scintillator have a strong effect on the energy dependent light yield proportionality, indicating that atomistic defects, resulting in trapping and de-trapping during carrier migration, exciton formation and transport substantially control the light

TABLE I

Non-Proportionality MEASUREd for SEVERAL CE-Doped Garnets

\begin{tabular}{|c|c|c|c|c|}
\hline Scintillator & $\eta_{\mathrm{e} / \mathrm{h}}^{\mathrm{a}}$ & $(\mathrm{dE} / \mathrm{dx})_{\mathrm{BIRKS}}^{\mathrm{b}}$ & $\begin{array}{c}\mathrm{R}_{\mathrm{NP}}(\%) \\
\text { predicted }\end{array}$ & $\begin{array}{c}\text { LY } \\
(\mathrm{Ph} / \mathrm{keV})\end{array}$ \\
\hline $\begin{array}{c}\text { GYGAG }(\mathrm{Ce}=0.02) \\
\text { Ceramic, } \\
\text { Vacuum sintered }\end{array}$ & $18.7 \%$ & $\begin{array}{c}625 \\
\mathrm{MeV} / \mathrm{cm}\end{array}$ & 2.49 & 50 \\
\hline $\begin{array}{c}\text { GYGAG }(\mathrm{Ce}=0.002) \\
\text { Ceramic, } \\
\text { Vacuum sintered }\end{array}$ & 18.7 & 909 & 2.15 & 33 \\
\hline $\begin{array}{c}\text { GYGAG }(\mathrm{Ce}=0.02) \\
\text { Ceramic, } \\
\mathrm{O}_{2} \text { sintered }\end{array}$ & 10 & 1000 & 1.72 & 40 \\
\hline$Y A G(C e)$ Ceramic & 10 & 526 & 2.44 & 30 \\
\hline $\begin{array}{c}G G A G(C e) \\
\text { Ceramic }\end{array}$ & 21 & 400 & 3.08 & 50 \\
\hline Vacuum sintered & & & & \\
\hline $\begin{array}{c}G G A G(C e) \\
\text { Single crystal }\end{array}$ & 0 & 434 & 3.12 & 60 \\
\hline
\end{tabular}

${ }^{a}$ Efficiency of exciton formation after carrier thermalization [14] bexciton-exciton annihilation via Birks' mechanism [14]. 
yield proportionality. Previously we described considerable variation among the light yield proportionality for multiple crystals of $\mathrm{NaI}(\mathrm{Tl})$ [12], but few other studies of the effect of fabrication conditions on light yield proportionality have yet been reported. In particular, for the transparent ceramic garnets, a fraction of the excitons that successfully migrate to $\mathrm{Ce}^{3+}$ are formed after thermalization, as is indicated by their large $\eta_{\text {eh }}$ values in the $10-19 \%$ range. Exciton-exciton annihilation, thought to occur in the sub-nanosecond regime in the scintillation process, is mitigated in the oxygen sintered ceramic, while being most severe in the GGAG(Ce) single crystal.

\section{E. Radiation Hardness Study}

Color center formation upon exposure to ionizing radiation is a concern for medical and high energy physics applications. To address this, several scintillators were exposed to radiation from a $9 \mathrm{MeV}$ Brehmsstrahlung source, and their optical absorption before and after exposure measured. Figure 9 shows that the GYGAG(Ce) ceramics did not darken with exposure, while a glass scintillator and a plastic scintillator exhibit marked new absorption bands. The total dose administered to the samples, all exposed in a single experiment, was $53 \mathrm{MR}$.

\section{CONCLUSION}

GYGAG(Ce) transparent ceramics have been fabricated with excellent transparency and uniformity at sizes $>2 \mathrm{in}^{3}$.
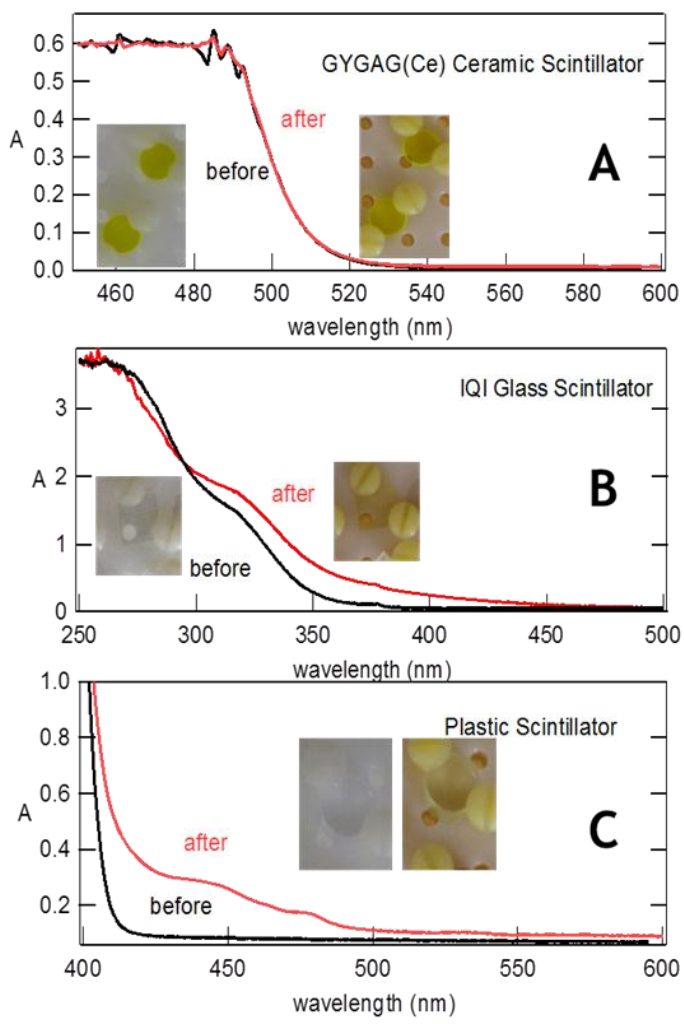

Fig. 9. (A) For GYGAG(Ce) ceramics, no radiation-induced darkening / color centers are observed In contrast, (B) glass and (C) plastic scintillators colored significantly.
Gd-based garnet scintillators offer energy resolution and stopping power superior to $\mathrm{NaI}(\mathrm{Tl})$ and are free of intrinsic self-radioactivity. Both PMT and silicon photodiode readout may be used for instrument development. Detailed studies of the trap state energetics and distribution will be useful to understand the strong dependence on fabrication conditions observed in the light yield non-proportionality, to optimize the composition and fabrication conditions in order to achieve high energy resolution, large volume Gd-garnet scintillators. Integration of $\mathrm{GYGAG}(\mathrm{Ce})$ transparent ceramics into high radiation rate experiments should be straightforward as no measurable darkening was observed even at high accumulated dose.

\section{ACKNOWLEDGMENTS}

We appreciate the help from Benjamin Sturm with initial measurement of the Cerium-doping series garnet samples. Thanks to Roger Perry and Keith Lewis for assistance with the radiation hardness testing.

\section{REFERENCES}

[1] Cherepy, N.J.; Kuntz, J.D.; Seeley, Z.M.; Fisher, S.E.; Drury, O.B.; Sturm, B.W.; Hurst, T.A.; Sanner, R.D.; Roberts, J.J.; Payne, S.A., "Transparent ceramic scintillators for $\gamma$ spectroscopy and radiography," Proc. SPIE, 7805, 7805-01 (2010).

[2] N.J. Cherepy, S.A. Payne, B.W. Sturm, S.P O’Neal, Z.M. Seeley, O.B. Drury, L.K. Haselhorst, B.L. Rupert, R.D. Sanner, P.A. Thelin, S.E. Fisher, R. Hawrami, K.S. Shah, A. Burger, J. O. Ramey, L.A. Boatner, "Performance of Europium-Doped Strontium Iodide, Transparent Ceramics and Bismuth-loaded Polymer Scintillators," Proc. SPIE, 8142, 81420W (2011).

[3] J. Kindem, R. Conwell, Z.M. Seeley, N.J. Cherepy, S.A. Payne, "Performance Comparison of Small GYGAG(Ce) and CsI(TI) Scintillators with PIN Detectors," IEEE Nuclear Science Symposium, Conf. Record, (2011).

[4] Dorenbos, P. "Electronic structure and optical properties of the lanthanide activated $\mathrm{RE}_{3}\left(\mathrm{Al}_{1-\mathrm{x}} \mathrm{Ga}_{\mathrm{x}}\right)_{5} \mathrm{O}_{12}(\mathrm{RE}=\mathrm{Gd}, \mathrm{Y}, \mathrm{Lu})$ garnet compounds," J. Luminescence, in press (2012).

[5] N.J. Cherepy, S.A. Payne, S.J. Asztalos, G. Hull, J.D. Kuntz, T. Niedermayr, S. Pimputkar, J.J. Roberts, R.D. Sanner, T.M. Tillotson, E. van Loef, C.M. Wilson, K.S. Shah, U.N. Roy, R. Hawrami, A. Burger, L.A. Boatner, W.-S. Choong, "Scintillators with Potential to Supersede Lanthanum Bromide," IEEE Trans. Nucl. Sci., 56, 873-880, (2009).

[6] K. Kamada, T. Yanagida, J. Pejchal, M. Nikl, T. Endo, K. Tsutsumi, Y. Fujimoto, A. Fukabori, A. Yoshikawa, "Crystal Growth and Scintillation Properties of Ce Doped $\mathrm{Gd}_{3}(\mathrm{Ga}, \mathrm{Al})_{5} \mathrm{O}_{12}$ Single Crystals," IEEE Trans. Nucl. Sci., 59, 2112-2115, (2012).

[7] G. Zhao, X. Zeng, J. Xu, Y. Xu, and Y. Zhou, "Characteristics of large-sized Ce:YAG scintillation crystal grown by temperature gradient technique," J. Cryst. Growth, 253, 290-296, (2003).

[8] K. Kamada, T. Yanagida, T. Endo, K. Tsutsumi, Y. Usuki, M. Nikl, Y. Fujimoto, A. Fukabori, A. Yoshikawa, "2 inch diameter single crystal growth and scintillation properties of Ce: $\mathrm{Gd}_{3} \mathrm{Al}_{2} \mathrm{Ga}_{3} \mathrm{O}_{12}$," J. Crys. Growth, 352, 88-90 (2012).

[9] B. W. Sturm, N. J. Cherepy, O. B. Drury, P. A. Thelin, S. E. Fisher, S. A. Payne, A. Burger, L. A. Boatner, J. O. Ramey, K. S. Shah, and R. Hawrami, "Effects of packaging $\mathrm{SrI}_{2}(\mathrm{Eu})$ scintillator crystals," Nucl. Instr. Meth. A, 652, 242-246, (2011).

[10] B.W. Sturm, N.J. Cherepy, O.B. Drury, P.A. Thelin, S.P. O’Neal, S.A. Payne, A. Burger, L.A. Boatner, J.O. Ramey, K.S. Shah, R. Hawrami, "Characteristics of undoped and europium-doped $\mathrm{SrI}_{2}$ scintillator detectors," IEEE Nuclear Science Symposium, Conf. Record, (2011).

[11] J. Glodo, E. V. van Loef, N. J. Cherepy, S. A. Payne, and K. S. Shah, "Concentration Effects in Eu Doped $\mathrm{SrI}_{2}$, " IEEE Trans. Nucl. Sci. 57, 1228-1232, (2010). 
[12] G. Hull, W.-S. Choong, W. W. Moses, G. Bizarri, J. D. Valentine, S. A. Payne, N. J. Cherepy, and B. W. Reutter, "Measurements of $\mathrm{NaI}(\mathrm{Tl})$ electron response: Comparison of different samples," IEEE Trans. Nucl. Sci, 56, 331-336 (2009).

[13] G.Bizarri, N.J. Cherepy, W.S. Choong, G. Hull, W.W. Moses, S.A. Payne, J. Singh, J.D. Valentine, A.N Vasiliev, R.T. Williams, "Progress in Studying Scintillator Proportionality Phenomenological Model," IEEE Trans. Nucl. Sci. 56, 2313-2320 (2009).

[14] Payne S.A.; Moses W.W.; Sheets S.; Ahle, L.; Cherepy, N.J.; Sturm, B.; Dazeley, S.; Bizarri, G.; Choong, W.-S.,

"Nonproportionality of Scintillator Detectors: Theory and Experiment. II ," IEEE Trans. Nucl. Sci., 58, 3392-402 (2011).

[15] ZM Seeley, NJ Cherepy, SA Payne, "Homogeneity of Gd-Based Garnet Transparent Ceramic Scintillators for Gamma Spectroscopy," J. Crystal Growth, in press (2012).

[16] W.-S.Choong,K. M. Vetter,W.W.Moses, S. A. Payne, N. J. Cherepy, J. D. Valentine, and G. Hull, "Design of a facility for measuring scintillator non-proportionality," IEEE Trans. Nucl. Sci., 55,1753-1758, (2008).

[17] W.-S. Choong, G. Hull, W. W. Moses, K. M. Vetter, S. A. Payne, N. J. Cherepy, and J. D. Valentine, "Performance of a facility for measuring scintillator non-proportionality," IEEE Trans. Nucl. Sci., 55, 1073-1078, (2008).

[18] N. J. Cherepy, S. A. Payne, B.W. Sturm, O. B. Drury, S. P. O'Neal, P.A. Thelin, K. S. Shah, R. Hawrami, M. Momayezi, B. Hurst, A. Burger, B. Wiggins, P. Bhattacharya, L. A. Boatner, J. O. Ramey, "Instrument Development and Gamma Spectroscopy with Strontium Iodide," IEEE Trans. Nucl. Sci., in press (2012). 